\title{
BIOETANOL DARI LIMBAH BIJI DURIAN (Durio zibethinus)
}

\author{
BIOETHANOL FROM WASTED DURIAN SEED (Duriozibethinus)
}

\author{
Murniati*, Sri Seno Handayani, Dwi Kartika Risfianty \\ Program Studi Kimia, FMIPA Universitas Mataram \\ Jalan Majapahit 62 Mataram 83125 NTB, Indonesia \\ *E-mail: murni chem12@yahoo.com
}

Diterima: 25 Juni 2018. Disetujui: 18 September 2018. Dipublikasikan: 30 September 2018

\begin{abstract}
Telah dilakukan penelitian pembuatan bioetanol dari limbah biji Durian (Durio zibethinus). Penelitian ini bertujuan untuk mengetahui apakah limbah biji Durian dapat dijadikan sebagai bahan baku pembuatan bietanol serta mengetahui pengaruh $\mathrm{pH}$ pada proses fermentasi. Penelitian ini menggunakan biji Durian yang dihidrolisis dengan $\mathrm{H}_{2} \mathrm{SO}_{4} 2,5 \%$ selama 3 jam pada suhu $70{ }^{\circ} \mathrm{C}$, kemudian diukur kadar glukosa dan difermentasi pada variasi $\mathrm{pH}=3,4,5$, dan 6 selama 48 jam. Hasil penelitian menunjukkan bahwa Biji Durian memiliki kadar pati yang berlimpah sebesar 45,85\%, sehingga bahan tersebut mampu diolah dan difermentasi untuk menghasilkan bioetanol. Kadar bioetanol yang dihasilkan pada penelitian ini memiliki kadar maksimal $47,02 \%$ dengan kondisi optimum $\mathrm{pH}$ fermentasi $=4$.
\end{abstract}

Kata kunci: Biji Durian, Bioetanol, pH Fermentasi

\begin{abstract}
Synthesis of bioethanol from Durian Seeds (DurioZibethinus)has been conducted. This study aims to makebietanolfrom wasteddurian seeds and to determine the effect of $\mathrm{pH}$ in fermentation process. This hydrolyzed durian seed was processed with $\mathrm{H}_{2} \mathrm{SO}_{4} 2.5 \%$ for 3 hour at $70{ }^{\circ} \mathrm{C}$, next the levels of glucose was measured and continuously fermented at various $\mathrm{pH}$ level 3, 4, 5, and 6 for 24 hours. The result shows that durianseed has $45,85 \%$ pati levels, therefore it is suitable for bioetanol production. The maximum bioetanollevel is $47,02 \%$ with the optimum condition of fermented $\mathrm{pH}=4$.
\end{abstract}

Keywords: Durian Seeds, Bioethanol, pH fermentation.

\section{PENDAHULUAN}

Bioetanol merupakan etanol yang berasal dari sumber hayati misalnya tebu, nira sorgum, ubi kayu, garut, ubi jalar, jagung, jerami, dan kayu. Bahan baku pembuatan bioetanol terdiri dari bahan-bahan yang mengandung pati, karbohidrat, glukosa, dan selulosa [1-4]. Tetapi disisi lain penggunaan bahan baku tersebut secara besarbesaran dapat mengganggu kebutuhan pangan karena bahan yang mengandung pati, karbohidrat, glukosa, dan selulosa sebagian besar merupakan bahan pangan. Oleh karena itu, diperlukan bahan baku lain yang lebih efektif dan efisien yang tidak berfungsi sebagai bahan pangan, salah satunya adalah biji Durian.

Pemanfaatan biji Durian saat ini cukup beraneka ragam mulai bahan pangan hingga bioenergi. Buah Durian terdiri dari 30\% limbah yang berupa kulitdanbiji Durian. Sehinggadari jumlah limbah tersebut dapat dikatakan cukup banyak dan akan menjadi sangat potensial jika dapat dimanfaatkan secara tepat. Biji Durian banyak mengandung pati sehingga sangat dimungkinkan untuk dimanfaatkan menjadi bioetanol [5]. Bioetanol dapat diproduksi dari zat pati atau amilum $\left(\mathrm{C}_{6} \mathrm{H}_{10} \mathrm{O}_{5}\right)_{\mathrm{n}}$ yang dihidrolisa menjadi glukosa kemudian difermentasi dengan mikroorganisme seperti Saccaromices cereviceae pada temperatur $27{ }^{\circ} \mathrm{C}-30{ }^{\circ} \mathrm{C}$ atau pada suhu kamar [6-7].

Pada proses fermentasi ubi garut pada $\mathrm{pH} 4,5$ yang menghasilkan kadar etanol sebesar $62,7 \%$ [8] dan $\mathrm{pH}$ pada pati biji nangka merupakan faktor yang sangat berpengaruh terhadap proses pembuatan bioetanol dan menghasilkan etanol sebesar 43,3\% dengan bantuan bakteri Saccaromices cereviceae [9]. Selain menggunakan bakan baku yang mengandung pati, bioetanol juga dapat diproduksi dari bahan baku seperti nirasorgum yang difermentasikan pada $\mathrm{pH} 5$ dengan waktu fermentasi selama 7 hari dan menghasilkan etanol sebesar $11,7 \%$ [12]. Dengan bahan baku yang berbeda yaitu biji Durian, pengaruh $\mathrm{pH}$ akan berpengaruh terhadap berkembangnya ragi Saccaromycescereviceae selama proses fermentasi berlangsung, sehinggadidapatkan kadar etanol yang lebih tinggi.

Proses pembuatan bioetanol terjadi dalam tiga tahap. Tahap pertama adalah persiapan bahan baku, yang berupa proses hidrolisis selulosa menjadi glukosa dengan cara enzimatis atau dengan asam encer atau pekat. Tahap kedua berupa proses fermentasi yaitu mengubah glukosa menjadi etanol sedangkan tahap ketiga yaitu pemurnian hasil dengan destilasi [14]. 
Tujuan dari penelitian ini adalah untuk mengetahui apakah limbah biji Durian dapat dimanfaatkan sebagai bahan baku pembuatan bioetanol dan untuk mengetahui pengaruh $\mathrm{pH}$ pada proses pembuatan bioetanol dari biji Durian.

\section{METODE PENELITIAN}

\section{Bahan}

Bahan-bahan yang digunakan pada penelitian ini adalah limbah biji Durian, ragi (Saccaromyces cereviceae), $\mathrm{NaOH}, \mathrm{H}_{2} \mathrm{SO}_{4}(2,5 \%)$, urea, $\mathrm{KH}_{2} \mathrm{PO}_{4}$, aquades, Pereaksi Nelson A, Pereaksi Nelson B dan arsenomolibdat.

\section{Alat}

Peralatan yang digunakan pada penelitian ini adalah seperangkat alat destilasi, alat-alat gelas, pipet tetes, sendok, kertas saring, $\mathrm{pH}$ meter, shaker bath, penangas air, UV-VISIBEL UVICON dan GC-MS.

\section{Cara Kerja}

\section{Persiapan sampel}

Perlakuan fisik terhadap biji Durian meliputi pencucian, pengupasan, pemotongan, dan pengeringan. Pencucian dilakukan untuk menghilangkan sisa-sisa daging buah Durian yang masih menempel pada biji, kemudian pengupasan kulit biji untuk mendapatkan biji Durian yang benar-benar putih. Kemudian dilakukan pemotongan dan pengeringan. Selanjutnya penentuan kadar air dan pati.

Kandungan air pada sampel dapat diketahui dengan melakukan perhitungan sebagai berikut :

$\%$ Kadar Air $=\frac{a-b}{a} \times 100 \%$

Keterangan Berat awal sampel dijemur (a) Berat konstan sampel di oven (b)

\section{Hidrolisis Pati}

Proseshidrolisis diawali dengan memasukan 25 gram sampel biji Durian kemudian ditambahkan $\mathrm{H}_{2} \mathrm{SO}_{4}$ dengan konsentrasi 2,5\%. Selanjutnya dipanaskan dengan penangas air selama 3 jam pada suhu $70^{\circ} \mathrm{C}$.

\section{Penentuan Kadar Glukosa}

Disiapkan larutan glukosa standar dengan konsentrasi masing-masing 5\%, 10\%, 15\%, 20\% dan $25 \%$. Sebanyak 7 tabung reaksi (5 tabung untuk standar dan 2 tabung untuk sampel) yang bersih dan kering, kemudian masing-masing tabung diisi dengan $1 \mathrm{~mL}$ larutan glukosa standar. Ke dalam setiap tabung, ditambahkan $1 \mathrm{~mL}$ pereaksi Nelson A dan Nelson B, lalu panaskan semua tabung dalam penangas air mendidih selama 20 menit. Semua tabung dikeluarkan dan dinginkan bersama-sama dengan memasukkan ke dalam gelas kimia yang berisi air dingin, sehingga suhu tabung mencapai $25{ }^{\circ} \mathrm{C}$. Setelah dingin, ditambahkan ke dalam setiap tabung $1 \mathrm{~mL}$ pereaksi Arsenomolibdat. Selanjutnya digojok sampai semua endapan $\mathrm{Cu}_{2} \mathrm{O}$ yang ada larut kembali. Setelah semua endapan $\mathrm{Cu}_{2} \mathrm{O}$ larut sempurna, ditambahkan $7 \mathrm{~mL}$ aquades dan digojok sampai homogen. Selanjutnya, diukur absorbansi (A) masing-masing larutan pada spektrofotometer UVVIS dengan panjang gelombang $540 \mathrm{~nm}$. Hasil pengukuran absorbansi selanjutnya dibuat kurva standar yang menunjukkan hubungan antara kadar glukosa dan absorbansi.

\section{Fermentasi}

Larutan hasil hidrolisis ditimbang sebanyak 8 gram, kemudian ditambahkan dengan 5 gram ragi, 2 gram urea dan 2 gram $\mathrm{KH}_{2} \mathrm{PO}_{4}$. Kemudian ditambahkan dengan $200 \mathrm{ml}$ aquades. Larutan yang

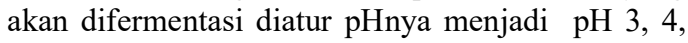
5 , dan 6 dengan penambahan $\mathrm{NaOH}$. Setelah larutan mencapai $\mathrm{pH}$ yang diinginkan, larutan ditutup rapat dan dishaker selama 24 jam dengan suhu $30^{\circ} \mathrm{C}$. Setelah dishaker selama 24 jam, larutan didiamkan kembali selama 24 jam didalam ruang gelap dengan suhu kamar.

Larutan hasil fermentasi disaring, kemudian filtratnya dimasukkan kedalam labu alas bundar yang disambungkan dengan rangkaian alat destilasi. Kemudian filtrat didestilasi dengan suhu $78{ }^{\circ} \mathrm{C}$ selama 3 jam. Kadar etanol hasil destilasi kemudian diukur dengan menggunakan instrumen UV-VIS pada panjang gelombang $214 \mathrm{~nm}$.

\section{Analisis GC-MS}

Etanol yang dihasilkan dari proses destilasi selanjutnya dianalisis dengan GC-MS.

\section{HASIL DAN PEMBAHASAN}

\section{Penentuan Kadar Air dan Pati}

Kandungan air dan pati pada biji Durian dapat dilihat pada gambar 1. Berdasakan gambar 1 bahwa kadar pati yang diperoleh dalam satu kilogram biji Durian yang sudah dibersihkan dari kulit arinya sebesar 54,15\%. Hal ini menunjukkan bahwa kandungan pati sangat besar, sehingga limbah biji Durian dapat dimanfaatkan menjadi bioetanol. Pati atau amilum $\left(\mathrm{C}_{6} \mathrm{H}_{10} \mathrm{O}_{5}\right) \mathrm{n}$ dihidrolisis menjadi glukosa kemudian difermentasi menjadi bioetanol.

\section{Hidrolisis pati}

Hidrolisis pati adalah penguraian senyawa pati menjadi senyawa yang lebih sederhana dengan bantuan air atau asam. Pada hidrolisis pati, air akan menguraikan molekul pati menjadi monomernya seperti glukosa [120]. Jika hidrolisis dilakukan dengan menggunakan bantuan katalis 
asam, maka larutan harus dinetralkan dengan larutan basa sehingga garam yang dihasilkan merupakan garam yang tidak berbahaya seperti garam kapur [15].

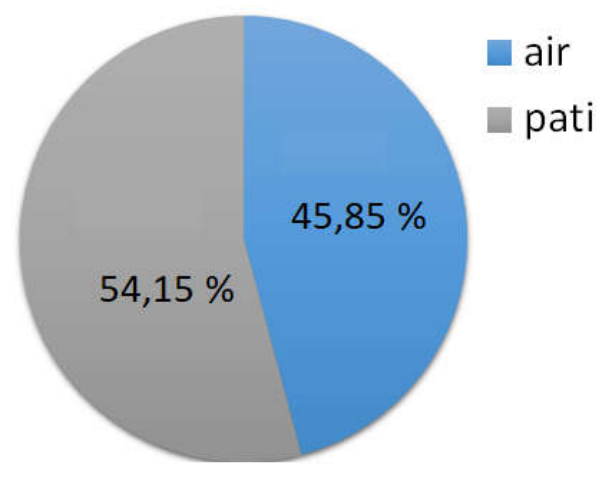

Gambar 1.Kadar air dan pati biji Durian

Penggunaan asam encer pada saat proses hidrolisis disebabkan karena penggunaan asam dengan konsentrasi yang terlalu tinggi akan mengakibatkan menurunnya hasil hidrolisis karena glukosa akan sangat mudah untuk diuraikan. Pada penelitian ini larutan asam yang digunakan sebagai larutan hidrolisis asam sulfat encer $\left(\mathrm{H}_{2} \mathrm{SO}_{4}\right) 2,5 \%$ yang dipanaskan dengan penangas air selama 3 jam dengan suhu $70{ }^{\circ} \mathrm{C}$. Proses hidrolisis ini menghasilkan larutan berwarna orange. Warna orange atau kekuningan yang dihasilkan pada sirup glukosa merupakan pengaruh asam dan lamanya proses hidrolisis yang akan membentuk 5 hidroksil metil furfural. Namun jika warna sirup menjadi kecoklatan, menandakan bahwa pada glukosa masih terkandung protein atau gugus amino. Penggunaan suhu yang tidak terlalu tinggipada saat proses hidrolisis karena jika menggunakan suhu yang sangat tinggi akan mengakibatkan glukosa pecah dan menghasilkan arang (furfural) sehingga larutan akan berubah menjadi lebih gelap (warna larutan hasil hidrolisis akan semakin tua) dan akan menghambat proses fermentasi [8,9]. Reaksi hidrolisis yang terjadi adalah:

$$
\left(\mathrm{C}_{6} \mathrm{H}_{10} \mathrm{O}_{5}\right) \mathrm{n}+\mathrm{nH}_{2} \mathrm{O} \longrightarrow \mathrm{nC}_{6} \mathrm{H}_{12} \mathrm{O}_{6}
$$

Reaksi yang terjadi antara pati dengan air ini terjadi sangat lambat sehingga penggunaan katalisator $\left(\mathrm{H}_{2} \mathrm{SO}_{4}\right)$ dibutuhkan untuk memperbesar kereaktifan air. Pemilihan hidrolisis dengan menggunakan katalisator asam encer selain ekonomis, hidrolisis dengan menggunakan asam encer relatif cepat dan menghasilkan rendemen gula lebih tinggi [15]. Hidrolisis menggunakan asam dengan konsentrasi tinggi juga akan menyebabkan gula yang dihasilkan akan diubah menjadi senyawa-senyawa furfural yang akan menghambat proses fermentasi.

\section{Penentuan Kadar Glukosa (Nelson - Somogy)}

Kadar glukosa hasil hidrolisis diukur dengan metode Nelson Somogy. Prinsip kerja metode ini adalah kuprioksida akan bereaksi menjadi kuprooksida $\left(\mathrm{Cu}_{2} \mathrm{O}\right)$ karena adanya gula reduksi (endapan merah bata). Jumlah endapan cuprooksida sebanding dengan jumlah gula reduksi [10]. Hasil hidrolisis ditambahkan dengan pereaksi Nelson A dan Nelson B kemudian dipanaskan selama 20 menit pada air mendidih yang bertujuan untuk mempercepat proses reduksi kupri oksida menjadi kuprooksida $\left(\mathrm{Cu}_{2} \mathrm{O}\right)$. Setelah dipanaskan kemudian tabung reaksi didinginkan hingga suhunya turun menjadi $25{ }^{\circ} \mathrm{C}$ agar reaksi berjalan stabil, karena apabila terlalu panas kemungkinan akan ada komponen senyawa yang rusak atau habis menguap. Kemudian ditambahkan kembali dengan reagen arsenomolibdad agar bisa bereaksi dengan endapan kuprooksida $\left(\mathrm{Cu}_{2} \mathrm{O}\right)$ yang menghasilkan larutan berwarna biru. Larutan tersebut kemudian digojok hingga endapan merah bata hilang secara perlahan dan ditambahkan dengan aquades yang bertujuan untuk mengurangi kepekatan larutan yang selanjutnya diuji dengan UV-VIS pada panjang gelombang $540 \mathrm{~nm}$.

Berdasarkan hasil pengukuran nilai absorbansi sebesar 0,0513, sehingga diperoleh kadar glukosa sebesar 13,8\%.

Kadar glukosa yang dihasilkan pada proses hidrolisis akan sangat menentukan kadar etanol yang dihasilkan dari proses fermentasi. Jika pada larutan hidrolisis kadar glukosa yang dihasilkan rendah, maka dapat dipastikan bahwa kadar etanolyang dihasilkan pada saat proses fermentasi juga akan rendah. Begitu juga sebaliknya, jika kadar glukosa tinggi, maka kadar etanol hasil destilasi juga akan semakin tinggi.

\section{Pengaruh pH Pada proses fermentasi}

Fermentasi merupakan kegiatan penguraian bahan-bahan karbohidrat dan menghasilkan gas karbondioksida [18]. Perubahan glukosa menjadi alkohol berlangsung melalui tahap glikolisis dan fermentasi alkohol. Pada jalur glikolisis, glukosa akan diubah menjadi asam piruvat, sedangkan pada jalur fermentasi alkohol, asam piruvat akan diubah menjadi alkohol.

Pada proses fermentasi, larutan hasil hidrolisis akan ditambahkan dengan urea $\left\{\mathrm{CO}\left(\mathrm{NH}_{2}\right)_{2}\right\}$ dan $\mathrm{KH}_{2} \mathrm{PO}_{4}$. Pertumbuhan ragi dipengaruhi oleh nutrien yang diberikan dengan perbandingan yang tepat. Nutrisi yang biasanya dibutuhkan oleh ragi berupa unsur karbon, nitrogen dan mineral. Nitrogen memiliki fungsi penting bagi ragi. Urea merupakan nutrien yang paling optimal bagi ragi karena urea memiliki kandungan nitrogen yang cukup tinggi yaitu sekitar 45-46\% [11-15]. Penggunaan $\mathrm{KH}_{2} \mathrm{PO}_{4}$ sebagai nutrien penyumbang 
mineral posfat bagi perkembangan sitoplasma Saccaromyces cereviceae, sehingga ragi mampu bekerja maksimal dengan adanya nutrien selama proses fermentasi. Proses fermentasi sampel basah dan kering dilakukan selama 48 jam (2 hari). Pada hari pertama larutan fermentasi dishaker dengan tujuan agar larutan bercampur homogen dan diberikan suhu $30^{\circ} \mathrm{C}$ sehingga menghasilkan larutan berwarna putih kekuningan. Penggunaan suhu yang relatif rendah bertujuan agar Saccaromyces cereviceae dapat bekerja dengan maksimal. suhu terbaik untuk melakukan proses fermentasi dengan Saccaromyses cereviceae yaitu pada suhu $28^{\circ} \mathrm{C}$ $30^{\circ} \mathrm{C}[21]$.

Selama proses fermentasi berlangsung, pada dasar tabung terdapat endapan putih yang diketahui sebagai mikroba Saccaromices cereviceae pada ragi yang mati selama proses fermentasi berlangsung.Kurva hubungan antara $\mathrm{pH}$ fermentasi dengan kadar etanol yang dihasilkan pada proses fermentasi.

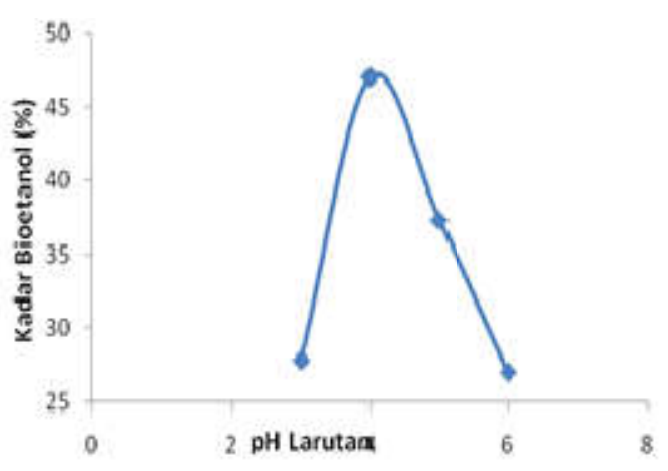

Gambar 2. Pengaruh $\mathrm{pH}$ terhadap kadar etanol

BerdasarkanGambar 2, kadaretanol yang dihasilkan pada poses fermentasi yang paling tinggi ditunjukkan pada $\mathrm{pH} 4$ sebesar $47,02 \%$. Penurunan kadar etanol pada $\mathrm{pH}$ diatas dan dibawah $\mathrm{pH} 4$ disebabkan enzim yang dihasilkan oleh ragi roti sebagai penghasil Saccaromyces cereviceae tidak mengalami proses perkembangbiakan dengan baik pada $\mathrm{pH}$ tersebut, sehingga Saccaromyces cereviceae yang terbentuk juga dalam jumlah yang tidak maksimal. Hal tersebut dikarenakan Saccaromyces cereviceae memerlukan suhu 25$30^{\circ} \mathrm{C}$ dan $\mathrm{pH} 4-4,5$ agar dapat berkembang dengan baik. Selain itu, jumlah asam yang terlalu tinggi atau terlalu rendah akan mengakibatkan denaturasi protein pada mikroba yang mengakibatkan aktivitas enzim akan berkurang selama proses fermentasi berlangsung [22-23]. Konsentrasi bioetanol yang semakin menurun juga dipengaruhi konsentrasi gula reduksi yang semakin berkurang. Ketika laju fermentasi berlangsung cepat sementara terjadi kekurangan konsentrasi gula reduksi, sebagian ragi cenderung akan mengkonsumsi bioetanol, sehingga terjadi reaksi lanjutan dari bioetanol yang teroksidasi menjadi asam asetat.
Penurunan produksi etanol pada konsentrasi gula berlebih merupakan inhibisi substrat. Konsentrasi substrat yang tinggi akan mengurangi jumlah oksigen terlarut[22]. Dalam proses fermentasi, Saccaromyces cereviceae tetap membutuhkan oksigen meskipun dalam jumlah kecil untuk mempertahankan kehidupan dan menjaga konsentrasi sel agar tetap tinggi [4]

\section{Analisis Dengan GC-MS}

Untuk mengetahui hasil destilasi yang terbentuk, maka dilakukan pengujian sampel yang dihasilkan dengan GC-MS.
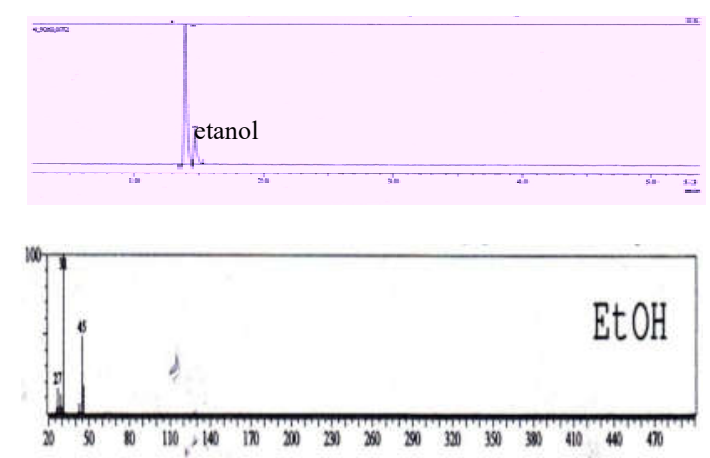

Gambar 3. Kromatogram GC-MS Bioetanol dan Spektrum Massa Bioetanol

Berdasarkan hasil analisis GC-MS muncul dua puncak, yaitu metanol dan etanol. Puncak tertinggi merupakan metanol dengan waktu retensi 1,388 dengan luas area sebesar $79,65 \%$ yang terdeteksi terlebih dahulu. Hal ini terjadi karena ukuran molekulnya yang lebih kecil dibandingkan dengan ukuran molekul pada puncak kedua yang terdeteksi pada luas waktu retensi 1,466 dengan luas area $20,35 \%$. Berdasarkan data kromatogram diatas diketahui bahwa kadar metanol yang terbentuk lebih tinggi dibandingkan dengan kadar etanol yang terbentuk. Adanya metanol tersebut merupakan hasil sampingan yang terbentuk pada saat proses fermentasi berlangsung. Pada ragi roti juga dapat tumbuh bakteri Archaebacteria methanogen yang dapat terbentuk pada proses fermentasi yang akan menghasilkan gas metana. Jika gas metana ini bereaksi dengan air, maka akan membentuk metanol.

Metanol juga memiliki titik didih yang lebih rendah dibandingkan dengan etanol yaitu $64,7^{\circ} \mathrm{C}$ sehingga pada saat proses destilasi berlangsung metanol akan lebih dulu menguap dibandingkan dengan etanol yang memiliki titik didih pada suhu $78,4^{\circ} \mathrm{C}$. Pada analisis MS, metanol dan etanol yang terdeteksi oleh GC akan diionisasi kembali oleh MS. Dengan adanya serangan elektron yang membentuk fragmen-fragmen, oleh MS akan terbaca menjadi puncak-puncak fragmen molekul yang bermuatan yang dapat diukur dengan 
rasio per muatan (m/z) yang dimiliki [24]. Penyusun senyawa-senyawa tersebut dapat dilihat pada gambar 4. Berdasarkan data fragmen tersebut dapat dilihat bahwa berat molekul etanol sebesar 46. Pada etanol terbentuk tiga fragmen yang dengan $\mathrm{m} / \mathrm{z} 27,38$ dan 45 .

\section{KESIMPULAN}

1. Biji Durian dapat digunakan sebagai bahan baku pembuatan bioetanol karena mengandung kadar pati yang cukup tinggi sebesar 54,14\%.

2. Kondisi optimum yang diperoleh pada variasi $\mathrm{pH}$ adalah pada $\mathrm{pH} 4$ dengan kadar bioetanol sebesar $47,02 \%$.

Sana penelitian ini adalah perlu dilakukan penelitian lebih lanjut dengan menggunakan sampel hidrolisis yang berupa cake dari biji Durian danoptimasifaktor-faktor yang berpengaruh pada prosesfermentasi agar mendapatkankadarbioetanol yang maksimal.

\section{DAFTAR PUSTAKA}

[1] Handayani, S. S., Hadi, S., \& Patmala, H. (2016). Fermentasi Glukosa Hasil Hidrolisis Buah Kumbi untuk Bahan Baku Bioetanol. Jurnal Pijar Mipa, 11(1).

[2] Kamali, S. R., Sumarlan, I., \& Fahrurazi, F. (2017). Pengolahan Sampah Plastik Metode Cracking Di Kelurahan Kelayu Jorong Lombok Timur. Jurnal Pijar Mipa, 12(2), 116-119.

[3] Hermiati, E., Mangunwidjaja, D., Sunarti, T. C., Suparno, O., \& Prasetya, B. (2017). Pemanfaatan biomassa lignoselulosa ampas tebu untuk produksi bioetanol. Jurnal Penelitian dan Pengembangan Pertanian, 29(4), 121-130.

[4] Anindyawati, T. (2017). Prospek enzim dan limbah lignoselulosa untuk produksi bioetanol. Jurnal Selulosa, 44(01).

[5] Nurfiana, F., Mukaromah, U., Jeannisa, V. C., \& Putra, S. (2009, November). Pembuatan bioethanol dari biji Durian sebagai sumber energi alternatif. In Seminar Nasional $V$ SDM Teknologi Nuklir. Yogyakarta: STTN-BATAN.

[6] Arnata, I., \& Anggreni, A. D. (2016). Rekayasa bioproses produksi bioetanol dari ubi kayu dengan teknik ko-kultur ragi tape dan Saccharomyces cerevisiae. Agrointek, 7(1), 21-28.

[7] Samsuri, M., Gozan, M., Mardias, R., Baiquni, M., Hermansyah, H., Wijanarko, A., ... \& Nasikin, M. (2009). Pemanfaatan sellulosa bagas untuk produksi ethanol melalui sakarifikasi dan fermentasi serentak dengan enzim xylanase. MAKARA,11(1), 17-24.
[8] Merina, F., \& Trihadiningrum, Y. (2011). Produksi bioetanol dari eceng gondok (Eichhornia crassipes) dengan Zymomonas mobilis dan Saccharomyces cerevisiae. In Prosiding Seminar Nasional Manajemen Teknologi XIII (Vol. 5).

[9] Amalia, Y., Muria, S. R., \& Chairul, C. (2014). Pembuatan Bioetanol Dari Limbah Padat Sagu Menggunakan Enzim Selulase Dan Yeast Saccharomyces Cerevisiae Dengan Proses Simultaneous Sacharificatian and Fermentation (SSF) Dengan Variasi Konsentrasi Substrat Dan Volume Inokulum. Jurnal Online Mahasiswa Fakultas Teknik Universitas Riau, 1(1), 1-8.

[10] Arianie, Lucy danIdiawati, Nora. 2011. Penentuan Lignin dan Kadar Glukosa Dalam Hidrolisis Organosolv dan Hidrolisis Asam.Jurnal Sains danTerapan Kimia, 5, 2, 140-150.

[11] Dhanang. 2013. Bioetanol: Bahan Bakar Masa Depan. Majalahonline BIOS.

[12] Endah, R.D., D. Sperisa, N. Adrian, danParyanto. 2007. Pengaruh Kondisi Fermentasi Terhadap Yield Etanol pada Pembuatan Bioetanol dari Pati Garut. MajalahIlmiahTeknik (GemaTeknik), 10, 2, $83-88$.

[13] Hepworth, M. 2005.Technical Environmental and Economic Aspects of Unit Operation for The production of Bioethanol From Sugar Beet in the United Kingdom, CET IIA Exercise 5, Corpus Christi College.

[14] Mastuti, E dan Setyawardhani, D.A. 2010. Pengaruh Variasi Temperatur Dan Konsentrasi Katalis Pada Kinetika Reaksi Hidrolisis Tepung Kulit Ketela Pohon. Jurnal Ekuilibrium, 9, 1, 23-27.

[15] Mulyati, Lolita. 2006. PupukdanPemupukan. Mataram: Mataram University Press.

[16] Nurfiana, F., Umi, M., Vicki, C.J., Putra, S. 2009. Seminar Nasional V SDM Teknologi Nuklir: Pembuatan Bioethanol dariBiji Durian sebagaiEnergiAlternatif. Yogyakarta. 2009. 669-676.

[17] Prasetyo, Elly. 2005. Sintesis Bioetanol dari Limbah Biji Durian (Duriozibethinus) DenganVariasi $p H$ pada Proses Fermentasi.UniversitasNegeri Semarang.

[18] Purwanto, Agung. 2012. Pembuatan bioetanol dari tepung biji nangka dengan sakarifikasi fermentasi fungi aspergilus niger dilanjutkan dengan fermentasi yeast saccharomyces cereviceae. Universitas Diponegoro. Semarang.

[19] Putra, Asga. 2006. Produksi Etanol menggunakan Saccaromicescereviceae yang diimobilisasi dengan Agar Batang. 
InstitutTeknologiSepuluh November : Surabaya

[20] Roukas, T., 1996. Continuous ethanol production from nonsterilized carob pod extract by immobilized Saccharomyces cerevisiae on mineral kissiris using a tworeactor system. Applied Biochemistry and Biotecnology Journal, 59, 3, 299-307.

[21] Said, G. 1987. Bioindustri Penerapan Teknologi Fermentasi. Jakarta: MeltonPutra.

[22] Sari, RatnaPutriPuspita. 2009. Pembuatan Bioetanol dari Nira Sorgum dengan Proses Fermentasi. Universitas Diponegoro. Semarang.

[23] Sastrohamidjojo, Hardjono. 1991. Spektroskopi. Yogyakarta: Liberty.

[24] Yuniwati, Murni. Ismiyati, D. Kurniasih, R. 2011. Kinetika Reaksi Hidrolisis Pati Pisang Tanduk Dengan Katalisator Asam Klorida. JurnalTeknologi, 4, 2, 107-112. 